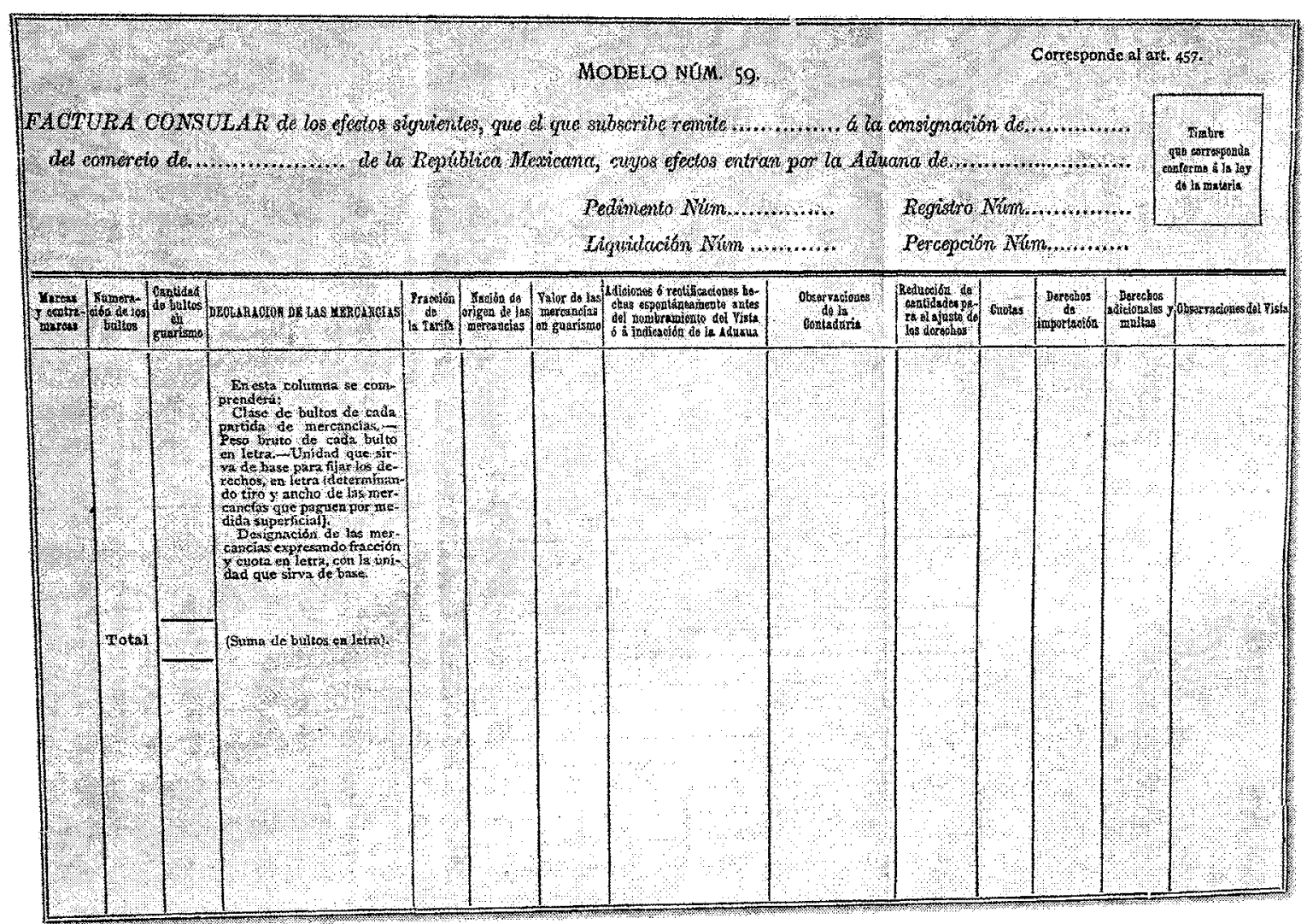

Tomada de Enrique Florescano (coord.), Historia general de las aduanas en Mêxico, México, Confederación de Asociaciones de Agentes Aduanales de la República Mexicana, 2004, p. 146. 
LUZ MARÍA UHTHOFF LÓPEZ

Doctora en Historia por la Universidad Nacional Autónoma de México. Profesora titular de tiempo completo en la Universidad Autónoma Metropolitana-Iztapalapa. Publicó el libro Las finanzas públicas durante la revolución. El papel de Luis Cabrera y Rafael Nieto al frente de la Secretaría de Hacienda, México, UAM-Iztapalapa, 1997. Así como diversos artículos en revistas especializadas y capítulos de libro. Desempeñó el cargo de coordinadora de la licenciatura en Historia de la UAM-Iztapalapa y de coordinadora del Posgrado en Humanidades, Línea de Historia, en la misma institución. Miembro del Sistema Nacional de Investigadores. Vocal de la Asociación Mexicana de Historia Económica. Su línea de investigación se dirige hacia la historia institucional y económica de México, siglos xIx y xx.

\section{Resumen}

Este trabajo analiza la relación entre la fiscalidad y el comportamiento del comercio exterior en los años de 1872 a 1930 . Especial énfasis se hace en la normatividad de la política arancelaria y la relación entre la dinámica política, el sistema fiscal y los impuestos al comercio exterior. Durante este periodo se observa, por un lado, una continuidad entre el antiguo régimen y la etapa de la revolución: el comercio exterior se mantuvo, incluso algunas ramas experimentaron un gran desarrollo y, por lo tanto, los impuestos exteriores continuaron siendo importantes. No obstante, también se registró una tendencia a la baja en los impuestos provenientes de este sector, y una disminución de su importancia en el conjunto de los ingresos federales, lo que indica que existió entre los gobiernos de esos años, tanto de la primera como de la segunda etapa, la preocupación de no depender solamente de éstos, aumentando las fuentes alternativas de ingresos internos, como es el caso del impuesto del timbre y del impuesto sobre la renta. 


\title{
LOS IMPUESTOS AL COMERCIO EXTERIOR EN MÉXICO EN LA ERA DE LAS EXPORTACIONES, 1872-1930*
}

\author{
Luz María Uhthoff López
}

\begin{abstract}
7 n México, como en América Latina, durante el siglo XIx los im4 puestos al comercio exterior, principalmente a las importaciones, constituyeron la base de los ingresos públicos federales. La preferencia por estos gravámenes mostraba la debilidad del sistema de tributación y la imposibilidad de obtener ingresos de fuentes internas, debido a la inestabilidad política, al poco crecimiento de la economía y a la herencia de la estructura tributaria colonial.

En las últimas décadas del siglo decimonónico tiene lugar una serie de cambios en la política económica que buscan, entre otros objetivos, hacer que las finanzas públicas dependan menos de los derechos sobre comercio exterior. Entre las medidas adoptadas destacan el establecimiento del impuesto del timbre y el arreglo de la deuda externa. ${ }^{1}$ Es durante el porfiriato cuando se consolidan estas medidas, permitiendo que la política comercial ${ }^{2}$ vaya más allá de un fin meramente recaudatorio, para ser parte de una política económica que permita orientar el crecimiento de determinados sectores de la economía, particularmente favorecer al sector comercial y manufacturero. Paralelamente, el mercado mundial registra un acelerado crecimiento debido a una revolución en
\end{abstract}

* Una primera versión de este trabajo se presentó en el 51 Congreso Internacional de Americanistas, Santiago de Chile, julio de 2003. También, agradezco los valiosos comentario de los dictaminadores del artículo.

Carmagnani, Estado, 1994 y Pérez, "Ingresos", 1982.

${ }^{2}$ Sobre el papel y la importancia de la política comercial de estos años véase Riguzzi, ¿Reciprocidad?, 2003 . 
tecnología y en transportes, así como una serie de cambios institucionales en los países europeos y Estados Unidos. ${ }^{3}$ Estos países demandan productos agrícolas y materias primas, mientras exportan innovaciones tecnológicas, capitales y recursos humanos hacia América Latina y otras regiones.

El objetivo de este trabajo es analizar la relación entre la fiscalidad y el comportamiento del comercio exterior entre 1872 y 1930 . Como es sabido, estos años se caracterizan como la "era de las exportaciones"4 o "la segunda conquista de América Latina", 5 por el aumento de las exportaciones y la fuerte integración de los países latinoamericanos a la economía mundial. En México, hay un gran crecimiento de este sector, se diversifican las exportaciones, también las importaciones y, en general, se estrecha la vinculación económica con las naciones europeas, pero sobre todo con Estados Unidos. Una serie de interrogantes surge en torno a esta temática, como icuáles son los cambios que se registran en la estructura de los impuestos exteriores? Y ¿qué relación existe entre los cambios políticos y el ciclo económico de expansión de las exportaciones? Estas preguntas guían la investigación; se hace especial énfasis en la normatividad de la política arancelaria, y la relación entre la dinámica política, el sistema fiscal y los impuestos al comercio exterior durante este periodo.

El trabajo se divide en tres partes. Una primera, ve en forma general las tendencias de los impuestos exteriores a partir de la reforma arancelaria de 1872 hasta 1913, año de la crisis del Estado porfirista. Analizar el comportamiento de los impuestos exteriores durante la lucha revolucionaria es el objetivo del segundo apartado, principalmente entre 1914 y 1917, y en el contexto de la primera guerra mundial. En la tercera parte se hace un estudio comparativo entre el primer periodo y el segundo, con el propósito de ver los cambios y continuidades en la política arancelaria.

La historiografía fiscal ha privilegiado el periodo del porfiriato; ${ }^{6}$ son pocos los trabajos que abordan los años de la revolución. Ello obedece en gran medida al problema de las fuentes. ${ }^{7}$ Por lo mismo, el trabajo es una aproximación, pues un estudio de los aranceles de este periodo debe contar con una reconstrucción más sistemática de las series de los im-

${ }^{3}$ Cárdenas, Ocampo y Thorp, Era, 2003, pp. 12-13.

${ }^{4}$ Cortês, "Crecimiento", 1993; Bulmer-Thomas, Historia, 2003; Cárdenas, Ocampo y Thorp, Era, 2003.

${ }^{3}$ Topik y Wells, Second, 1998.

${ }^{6}$ Desde el periodo del porfiriato se publican varias obras que abordan la temática de la fiscalidad en esos años. Al respecto véase Pérez, Fisscalidad, 1999.

De 1914 a 1923 las Memorias de Hacienda y las Cuentas del Tesoro Federal dejaron de hacerse. En particular para los años de 1914 a 1916 los registros estadísticos son irregulares. Otro problema es que por lo regular las cifras se presentan en pesos mexicanos, y en una época de caos monetarios e inflación, es difícil precisar el numerario que representan. 
puestos, dificultad que se puede superar para el periodo de 1872 a 1913, pero hay límites para los años posteriores. Es hasta mediados de la década de 1920 cuando se puede contar con estadísticas más confiables.

DESARROLLO Y TENDENCIAS DE LOS IMPUESTOS EXTERIORES, 1872-1913

En las últimas décadas del siglo XIX los derechos sobre el comercio exterior recayeron básicamente sobre las importaciones. Éstas representaron $95.5 \%$ en promedio anual, mientras que las exportaciones fueron $2.5 \%$ del total de los derechos sobre este sector. ${ }^{8}$ Los derechos de importación en estos años pasaron de 21918020 pesos en 1872 a 49237352 pesos en 1913, creciendo a más del doble. En contraste, los derechos a las exportaciones, descendieron en los mismos años de 1063700 pesos a 659831 pesos. Estas tendencias generales en los impuestos exteriores estuvieron vinculadas tanto a las fluctuaciones del mercado mundial como a la polí tica arancelaria. Así, observamos cómo las crisis cíclicas de 1873, 1882 $1884,1890-1892,1900$ y 1907 coincidieron con la baja de ingresos de este sector (cuadro 1)..$^{9}$

En lo que se refiere al comercio exterior hubo modificaciones en su estructura. Los nuevos requerimientos del mercado mundial, junto con las transformaciones políticas y económicas internas, permitieron una mayor diversificación de este sector. A la tradicional exportación de metales preciosos, principalmente la plata, se sumaron los metales industriales (cobre, plomo y zinc). Además, crecieron y se multiplicaron los productos agrícolas, como henequén, café, caucho, ixtle, vainilla, etc. También las importaciones se diversificaron; disminuyó la importancia de los artículos suntuarios, pero aumentaron las materias primas y los bienes de producción. ${ }^{10}$

En 1872 los impuestos exteriores representaron $58.7 \%$ del total de los ingresos. Para 1910 descendieron a $46.6 \%$ y para 1913 a $43.4 \%$ (cuadro 1 ). Ciertamente su descenso no fue un cambio espectacular, pero contrastaba con el crecimiento notable que, durante esos mismos años, tuvieron los impuestos interiores del timbre, al pasar de 14.1 a $31.7 \%$ del total de los ingresos.

${ }^{8}$ El 2\% restante correspondió a derechos especiales. Pêrez, "Ingresos", 1982, t. 1, p. 120

${ }^{9}$ Véase ibid., p. 127, y Carmagnani, Estado, 1994, p. 260

${ }^{9}$ Véase ibid., p. 127, y Carmagnani, Estado, 1994, p. 260.
${ }^{0}$ Se puede decir que esta nueva composición del comercio exterior mostraba una economía intermedia, en vías de industrialización. Si bien la historiografía tradicional señala que, mia intermedia, en vías de industrializacion. Si bien la historiografia tradicional señala que,
durante estos años, el estímulo que los Estados latinoamericanos dieron al sector exportador durante estos años, el estímulo que los Estados latinoamericanos dieron al sector exportador impidió el desarrollo de una industria nacional. Investigaciones recientes muestran, al contraro, que la promoción a las exportaciones en algunos parses de América Latha (Mexico, Brasí Sobre este punto volveremos más adelante. Cárdenas, Ocampo y Thorp, Era, 2003, p. 43. 
10 Luz María Uhthoff Lopez

CUADRO 1. INGRESOS FEDERALES, IMPUESTOS AL COMERCIO

EXTERIOR, IMPUESTOS A LAS IMPORTACIONES E IMPUESTOS A LAS EXPORTACIONES (MILES DE PESOS CORRIENTES)

\begin{tabular}{|c|c|c|c|c|c|c|c|}
\hline Años & $\begin{array}{l}\text { Ingresos } \\
\text { federales }\end{array}$ & $\begin{array}{c}\text { Impuestos } \\
\text { al comercio } \\
\text { exterior }^{\mathrm{n}}\end{array}$ & $P T I$ & $\begin{array}{c}\text { Impuestos } \\
\quad \text { a las } \\
\text { importaciones }\end{array}$ & $P T T$ & $\begin{array}{l}\text { Impuestos } \\
\quad \text { a las } \\
\text { exportaciones }\end{array}$ & $p_{T T}$ \\
\hline $1872-1873$ & 15739 & 9244 & 58.7 & 8128 & 51.6 & 1063 & 6.7 \\
\hline $1873-1874$ & 17900 & 11509 & 64.2 & 10354 & 57.8 & 885 & 4.9 \\
\hline $1874-1875$ & 17597 & 10126 & 57.5 & 9204 & 52.3 & 854 & 4.8 \\
\hline $1875-1876$ & 17266 & 9177 & 53.1 & 8393 & 48.6 & 726 & 4.2 \\
\hline $1876-1877$ & 17836 & 9319 & 50.6 & 8308 & 45.1 & 959 & 5.2 \\
\hline $1877-1878$ & 19772 & 13449 & 68.0 & 12367 & 62.5 & 1016 & 5.1 \\
\hline $1878-1879$ & 17811 & 10464 & 58.7 & 9518 & 53.4 & 885 & 4.9 \\
\hline $1879-1880$ & 21936 & 13438 & 61.2 & 12338 & 36.2 & 1029 & $4: 6$ \\
\hline $1880-1881$ & 25290 & 14739 & 58.2 & 13768 & 54.4 & 889 & 3.5 \\
\hline $1881-1882$ & 29347 & 18439 & 62.8 & 17520 & 59.7 & 711 & 2.4 \\
\hline $1882-1883$ & 32205 & 19058 & 59.1 & 18363 & 57.2 & 462 & 1.4 \\
\hline $1883-1884$ & 32451 & 17873 & 55.8 & 17325 & 53.3 & 326 & 1.0 \\
\hline $1884-1885$ & 29869 & 15705 & 52.5 & 15229 & 50.9 & 310 & 1.0 \\
\hline $1885-1886$ & 28797 & 15258 & 52.9 & 14852 & 51.5 & 257 & 0.9 \\
\hline 1886-1887 & 32126 & 17705 & 55.1 & 17268 & 53.7 & 263 & 0.8 \\
\hline $1887-1888$ & 35215 & 19315 & 54.8 & 18958 & 53.8 & 140 & 0.4 \\
\hline $1888-1889$ & 35218 & 19374 & 55.0 & 19063 & 54.1 & 88 & 0.2 \\
\hline $1889-1890$ & 40813 & 22.552 & 55.2 & 22181 & 54.3 & 98 & 0.2 \\
\hline $1890-1891$ & 38725 & 20958 & 54.1 & 20605 & 53.2 & 86 & 0.2 \\
\hline 1891-1892 & 38654 & 20811 & 53.8 & 20448 & 52.9 & 96 & 0.2 \\
\hline $1892-1893$ & 36916 & 17537 & 47.5 & 17187 & 46.5 & 91 & 0.2 \\
\hline $1893-1894$ & 39350 & 16897 & 42.4 & 15621 & 39.2 & 1037 & 2.6 \\
\hline 1894-1895 & 44.570 & 19681 & 44.1 & 18091 & 40.5 & 1227 & 2.7 \\
\hline $1895-1896$ & 51005 & 23439 & 45.9 & 21918 & 42.9 & 1078 & 2.1 \\
\hline $1896-1897$ & 51354 & 23639 & 45.4 & 21907 & 42.1 & 1244 & 2.3 \\
\hline $1897-1898$ & 52697 & 23284 & 44.18 & 21379 & 40.4 & 1414 & 2.6 \\
\hline 1898-1899 & 60139 & 28738 & 47.7 & 26969 & 44.8 & 1066 & 1.7 \\
\hline $1899-1900$ & 64261 & 29945 & 46.6 & 28247 & 43.9 & 872 & 1.3 \\
\hline $1900-1901$ & 62998 & 28434 & 45.1 & 26775 & 42.5 & 779 & 1.2 \\
\hline $1901-1902$ & 66147 & 28732 & 43.4 & 26914 & 40.6 & 863 & 1.3 \\
\hline $1902-1903$ & 76023 & 34.783 & 45.7 & 23857 & 43.2 & 845 & 1.1 \\
\hline $1903-1904$ & 86475 & 37436 & 49.2 & 35332 & 40.8 & 965 & 1.1 \\
\hline 1904-1905 & 92083 & 41028 & 44.5 & 38918 & 42.2 & 917 & 1.0 \\
\hline 1905-1906 & 101972 & 48842 & 47.8 & 46117 & 45.2 & 946 & 0.9 \\
\hline
\end{tabular}


Los impuestos al comercio exterior en México

\begin{tabular}{|c|c|c|c|c|c|c|c|}
\hline Años & $\begin{array}{l}\text { Ingresos } \\
\text { federales }\end{array}$ & $\begin{array}{l}\text { Impuestos } \\
\text { al comercio } \\
\text { exterior }^{\mathrm{a}}\end{array}$ & $P T T$ & $\begin{array}{l}\text { Impuestos } \\
\text { a las } \\
\text { importaciones }\end{array}$ & $P T I$ & $\begin{array}{l}\text { Impuestos } \\
\quad \text { a las } \\
\text { exportaciones }\end{array}$ & $P T I$ \\
\hline $1906-1907$ & 114286 & 55639 & 48.6 & 52332 & 45.7 & 1051 & 0.9 \\
\hline $1907-1908$ & 111771 & 55567 & 49.8 & 52363 & 46.8 & 859 & 0.7 \\
\hline $1908-1909$ & 98775 & 40567 & 41.0 & 37939 & 38.4 & 515 & 0.5 \\
\hline $1909-1910$ & 106328 & 49690 & 46.7 & 46566 & 43.8 & 501 & 0.4 \\
\hline $1910-1911$ & 111143 & 51873 & 46.6 & 48688 & 43.8 & 466 & 0.4 \\
\hline 1911-1912 & 105203 & 45341 & 43.1 & 42190 & 40.1 & 495 & 0.4 \\
\hline $1912-1913$ & 120958 & 52568 & 43.4 & 49237 & 40.7 & 659 & 0.5 \\
\hline $1917^{\mathrm{b}}$ & 96999 & 40229 & 41.5 & 23722 & 24.4 & 10835 & 11.1 \\
\hline 1918 & 146749 & 46393 & 31.6 & 26132 & 17.8 & 12690 & 8.6 \\
\hline 1919 & 200349 & 61932 & 30.9 & 41039 & 20.5 & 13194 & 6.5 \\
\hline 1920 & 238243 & 71992 & 30.2 & 55228 & 23.1 & 11031 & 4.6 \\
\hline 1921 & 279832 & 81105 & 28.9 & 74220 & 26.5 & 6865 & 2.4 \\
\hline 1922 & 286846 & 88451 & 30.9 & 57946 & 20.2 & 30505 & 10.7 \\
\hline 1923 & 283561 & 84070 & 29.5 & 63170 & 22.2 & 20900 & 7.3 \\
\hline 1924 & 272966 & 83664 & 30.6 & 62571 & 22.9 & 21093 & 7.7 \\
\hline 1925 & 336717 & 94914 & 28.1 & 76337 & 22.6 & 18577 & 5.5 \\
\hline 1926 & 309164 & 109686 & 35.3 & 93316 & 30.1 & 16370 & 5.2 \\
\hline 1927 & 295440 & 100969 & 34.1 & 89555 & 30.3 & 11414 & 3.8 \\
\hline 1928 & 299753 & 115007 & 38.3 & 104742 & 34.9 & 10265 & 3.4 \\
\hline 1929 & 322335 & 116001 & 35.8 & 107959 & 33.4 & 8042 & 2.4 \\
\hline 1930 & 288863 & 103641 & 35.8 & 97383 & 33.7 & 6258 & 2.1 \\
\hline
\end{tabular}

PTI= Porcentaje del total de los ingresos.

${ }^{a}$ Los impuestos al comercio exterior, además de los derechos a las importaciones y exporaduanales, cuyo mon derechos especiales, impuestos que cobraba la federación por servicios se incluye en los impuestos exteriores.

${ }^{b}$ Después de 1917 el año fiscal coincide con el año natural

Fuentes: Memoria, 1912; Ilustración, 1923; Memoria, 1926; México, 1932, y Pérez, "Ingresos", 1982 . 


\section{Luz Maria Uhthoff López}

Durante este periodo tuvieron lugar varias reformas arancelarias. ${ }^{11}$ Con la de 1872 se delineó una nueva política fiscal que perseguía establecer el derecho por cuota fija, abolir las prohibiciones, aumentar la lista de mercancías libres, entre otras medidas. ${ }^{12}$ Facilitar el intercambio fue su principal propósito. Para ello se liberalizaron varios productos o se aminoró su carga impositiva. El arancel de $1887^{13}$ reafirmó el sentido liberal, al aumentar el número de artículos permitidos y al reducir los impuestos a la importación, particularmente su efecto se vio en las materias primas y bienes intermedios. ${ }^{14}$ En el de $1891^{15}$ creció la lista de productos libres, entre los que destacaban nuevamente las materias primas, los bienes intermedios y de capital. Con ello se fortalecía la tendencia de liberalización de las importaciones, de tal modo que en esta década y la siguiente se consolidó una política arancelaria favorable a la industria vía sustitución de importaciones. ${ }^{16}$ En 1900 se establecieron cuotas proteccionistas para determinados productos de hierro. En el siguiente año, se redujeron las cuotas de las materias primas para la industria. ${ }^{17}$ Para 1905 , año en que México adoptó el patrón oro y desapareció la protección cambiaria, las autoridades hacendarias expresaban su interés en com pensar a los industriales por la pérdida de esa protección cambiaria. ${ }^{18}$ En junio del mismo año se reforma el arancel, bajando los gravámenes a bienes de capital y materias primas, y elevando las tasas de sectores in

${ }^{11}$ La política arancelaria fue codificada bajo la denominación de Ordenanzas General de Aduanas Mar 1885, 1887 y 1891, hasta 1930 se emitió la siguiente. Estas Ordenanzas fueron el marco legal con el que funcionaba el comercio exterior y eran aprobadas por el Congreso, no obstante el ejecutivo estuvo facultado para hacer modificaciones a las tarifas. De hecho, desde $1873 \mathrm{el}$ ejecu"Política", 2001, pp. 108-111. Véase también Cosío, Cuestión, 1940; Arroyo, Historia, 1937; Sierra y Martínez, Historia, 1973, y Riguzzi, dReciprocidad?, 2003.

eciprocidad?, 2003 1982, t. 1, p. 121; Kuntz, "Institutional", 2002, p. 166.

${ }_{13}$ t. 1, p. 121; Kuntz, "Institutional, 202, p. 166.

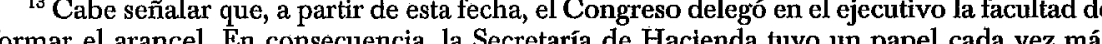
reftivo en el delineamiento de la política arancelaria. Para ello estableció la Dirección vez más de Aduanas en la Secretaría de Hacienda.

${ }_{14}^{14}$ Pérez, "Ingresos", 1982, t. 1, p. 123, y Márquez, "Impuestos", 2002, p. 3.

${ }_{15}$ Para Riguzzi esta ordenanza era una respuesta a los cambios tarifarios estadunidenses establecidos con el Arancel Mckinley que, entre otras medidas, imponía gravámenes a los metales exportados por México. Riguzzi, ¿Reciprocidad?, 2003, pp. 138-139.

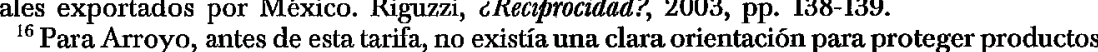
demandados por la industria nacional. A partir de 1892, fue patente esta intención. Arroyo, Historia, 1937, p. 20. Véase también Carmagnani, Estado, 1994, pp. 261-263; Beatty, Institutions, 2001, p. 46, y Kuntz, "Institutional", 2002, p. 172.

Arroyo, Historia, 1937, p. 21, y Kuntz, "Institutional", 2002, p. 173

${ }^{18}$ Este objetivo compensatorio fue muy evidente en la minería, cuyos efectos de la reforma fueron más drásticos. En general se disminuyen sus gravámenes y se exenta de derechos de importación a artículos y maquinaria destinada a esta industria. 
dustriales que se habían desarrollado al amparo de la política arancelaria y cambiaria de los años noventa. ${ }^{19}$ La tendencia fue eximir los bienes de producción y de consumo básico para paliar los efectos de las crisis económicas. En contraste, se aumentó la carga impositiva de los bienes suntuarios y mercancías que se producían en el país. Otro factor que permitió la protección de las manufacturas nacionales fue la devaluación de la plata. Su creciente baja en el mercado internacional hizo más competitiva la producción local frente a la extranjera.

Recientemente, los trabajos historiográficos de Graciela Márquez, Edward Beatty y Sandra Kuntz ${ }^{20}$ muestran el papel de la política arancelaria en el desarrollo industrial en la última década del siglo XIX. Para Beatty existió entre las elites políticas un interés de proteger y promover la industria nacional, anticipándose por media centuria a la política de sustitución de importaciones imperante a mediados del siglo $\mathrm{Xx}^{21}$

Así, a lo largo del porfiriato disminuyó la importancia en los ingresos totales de los impuestos sobre el comercio exterior, descenso que estuvo relacionado con una mayor apertura de la economía. En general se registró una baja de los derechos a las exportaciones y un aumento de los ingresos derivados de los derechos de las importaciones. Ciertamente, la política arancelaria tuvo el propósito de influir en la economía privada. El caso del desarrollo industrial es una muestra, pero también se estimuló a otras ramas económicas, como la minería y la agricultura de exportación. Los constantes cambios en los aranceles de importación reflejan este sentido, mientras las tarifas de exportación quedaron con poca variación. ${ }^{22}$ A diferencia del proteccionismo prevaleciente en la mayor parte del siglo XIX, estos años, sobre todo después de 1890, se caracterizaron por un proteccionismo moderado, ${ }^{23}$ desgravando productos de exportación ${ }^{24}$ y aumentando los derechos sobre bienes manufacturados. Con ello, a la vez que se estimulaba el intercambio comercial, se protegía la incipiente industria nacional. ${ }^{25}$ Los industriales y comerciantes fueron los

${ }_{20}^{19}$ Márquez, "Impuestos", 2002, p. 4.

${ }^{20}$ Márquez, Political, 2002; Beatty, Institutions, 2001, y Kuntz, "Institutional", 2002

${ }^{21}$ Para Beatty la politica arancelaria fue la clave, pues sin protección, ninguna reforma institucional hubiera sido suficiente para el desarrollo industrial. Beatty, "Commercial", 2002, p. 238 ${ }^{22}$ En general predominó la tendencia liberal de exentar las exportaciones. Aunque en la década de 1890 se gravó el henequén y el café. Al final del porfiriato sólo cinco producto estaban tasados: maderas de construcción y ebanistería, zacatón, chicle, guayule, pieles y cueros sin curtir. Pérez, "Ingresos", 1982, t. 1, pp. 138-144.

${ }^{23}$ Arroyo, Historia, 1937, p. 21, y Beatty, "Visiones", 2003, p. 56.
${ }^{4}$ En la exportación de los metales hubo importantes reducciones y eliminación de derechos. Para Carmagnani la liberación de exportaciones representó una forma de incentivar a los pesos. Carmagnani, Estado, 1994, p. 220.

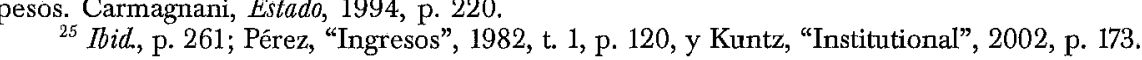


sectores más favorecidos. No obstante en los últimos años de este régimen sólo un grupo reducido de empresarios, los grupos más grandes y mejor organizados, eran los directamente apoyados con tasas arancelarias altas a sus competidores extranjeros. ${ }^{26}$

En los primeros años de la década de 1910 , con los cambios políticos y el inicio de la lucha revolucionaria, hubo cambios parciales en los aranceles. El gobierno de Madero, y después el de Huerta, buscaron contrarrestar los efectos de la guerra, aumentando los gravámenes a los impuestos interiores, como los tabacos y alcoholes. ${ }^{27}$

En cuanto a los impuestos exteriores, se aumentó uno adicional de 5\% a los derechos de importación. Fueron estos impuestos los primeros que resintieron los trastornos de la contienda, al disminuir en 1912 cerca de $20 \%$, debido a que los grupos rebeldes se apoderaron de algunas aduanas del norte.

Para 1914, con la crisis terminal del Estado porfirista, el panorama era más crítico. A partir de este año hubo un proceso de regionalización de las aduanas, que quedaron bajo el control de los jefes militares. Ciertamente el jefe del constitucionalismo, Venustiano Carranza, pretendió mantener una dirección centralizada de las fuentes de financiamiento, y su éxito dependió de lograr armar una red entre ciudades clave del país, principalmente controlando las aduanas terrestres y marítimas. En un principio tuvo el dominio de Veracruz, la aduana más importante de la república. Después dirigió su interés a las fronteras del norte, Sonora, Coahuila, Nuevo León y Tamaulipas, los puertos del Pacífico y del Golfo de México. $^{28}$ Además, el Primer Jefe tenía todas las atribuciones para legislar en materia económica. ${ }^{29}$

\section{LA REVOLUCIÓN, LA FISCALIDAD Y EL COMERCIO EXTERIOR}

El gobierno revolucionario ${ }^{30}$ estableció nuevas medidas arancelarias, cuyo fin principal era recaudatorio, dada la urgente necesidad de obtener recursos para la guerra. Diversos autores han señalado la importancia de

${ }^{26}$ Graciela Márquez señala que fueron los sectores de textiles, hierro y acero los más beneficiados. Márquez, "Impuestos", 2002, p. 10. Véase también Beatty, "Visiones", 2003. ${ }^{27}$ Un cambio importante en los impuestos del timbre, establecido por Madero en 1912, fue Zavala, "Impuestos", 1981, p. 329

${ }^{28}$ Hernández, "Militares", 1984, p. 188, y Zebadúa, Banqueros, 1994, p. 93.

${ }^{29}$ En Las Adiciones al Plan de Guadalupe se establecía que podía emitir todas las disposiciones y medidas encaminadas a las necesidades economicas. Córdoba, Ideología, 1973, pp. 447-452.

${ }^{30}$ Sólo se analizan las medidas adoptadas por el constitucionalismo, fuerza revolucionaria triunfadora, que delineó a lo largo de la contienda armada una política comercial más sistemática. 
estos gravámenes en una época en que no había otra fuente de ingresos. No obstante, por lo general, la historiografía sólo resalta el aporte de los impuestos del petróleo, dejando de lado otras contribuciones, como las de la minería y el henequén, que también fueron importantes. Cabe decir que la recaudación de los impuestos durante este periodo convulsivo estuvo sujeta a variables distintas a las imperantes en un periodo normal de desarrollo económico, como pueden ser el ciclo de producción de las economías exportadoras y su demanda en el mercado mundial. Con la revolución, también dependieron de los vaivenes de la lucha armada, del dominio del territorio logrado por la fuerza revolucionaria triunfante, el constitucionalismo, y, en general, de la recepción que hicieron las empresas extranjeras de los nuevos gravámenes cobrados por esta fuerza revolucionaria.

Otra circunstancia que acompañó la puesta en marcha de la política arancelaria fue que le permitió al gobierno constitucionalista desplegar su nacionalismo económico. Entre la nueva clase política en ascenso existió la preocupación de que los recursos naturales en manos de propietarios extranjeros fueran aprovechados por los mexicanos y, sobre todo, que el Estado tuviera una mayor participación en estas actividades. ${ }^{31}$ Esto se tradujo en una nueva legislación, que revindicó a favor de la nación los derechos del subsuelo, ${ }^{32}$ y en una política arancelaria de mayores impuestos a las economías exportadoras, en su mayor parte en manos de extranjeros.

LOS DERECHOS DE IMPORTACIÓN A LA BAJA

A diferencia del periodo anterior, con la contienda armada, disminuyó notoriamente la importancia de los impuestos a las importaciones, mientras que los de las exportaciones se incrementaron. Ciertamente ello obedeció a la drástica caída que en general sufrieron las importaciones durante esta etapa, pero sobre todo entre 1914 y 1915 . Una serie de factores internos como la desorganización del transporte, la disminución en

De alguna manera, se trata de una diferencia clave sobre sus adversarios villistas y zapatistas. Véase Hernández, "Militares", 1984; Zebadúa, Banqueros, 1994, y Uhthoff, Finanzas, 1998. ${ }^{31}$ Los encargados de Hacienda, Cabrera y Nieto, y el mismo Carranza, Primer Jefe del Ejército Constitucionalista, compartían la idea de que los mexicanos debían participar más en la explotación de sus recursos naturales, dominados la mayor parte por empresas extranjeras. Ka, Guerra, t. 1, 1982, p. 159; Meyer, 1972, Mexico, pp. 97-98, y Uhthoff, Finanzas, 1998, p. 128 En la Constitución de 1917 el artéculo 27 establece que este dominio es inalienable imprescriptible y que sólo el gobierno federal podría hacer concesiones a los particulares y a las
sociedades constituidas conforme a las leyes mexicanas. 
general del ritmo de la economía interna y la escasez de divisas que permitieran la compra de productos en el exterior, explican la caída de las importaciones. Además, la situación generada por la primera guerra mundial limitó las exportaciones europeas a México, pues estos países destinaron sus recursos a la producción bélica, disminuyendo la producción y exportación de bienes de producción y consumo. ${ }^{33}$

Entre los cambios registrados en las importaciones estaba la disminución de los bienes de producción. En contraste, crecieron las importaciones de bienes de consumo $y$, sobre todo, de equipo militar, ${ }^{34}$ aunque es difícil precisar el monto de este equipo, pues por lo regular entraba de contrabando. En lo que se refiere a los derechos de estas importaciones, sus modificaciones respondieron en gran medida a la gran presión social que se radicalizó con la lucha revolucionaria. Así se buscó paliar la gran carestía y la especulación de los bienes de consumo, principalmente en los años críticos de 1915 y 1916 . Si bien la práctica de bajar o la de exentar productos de primera necesidad no era nueva, pues se hacía durante el porfiriato en años de crisis, lo relevante era el gran número de artículos que eliminaron sus derechos de importación: más de 100 artículos de primera necesidad, entre los que destacaban el maíz, el frijol, el trigo y el arroz. ${ }^{35}$

Durante los primeros años de la guerra, como es de suponer, el fin recaudatorio imperó en el diseño de la política arancelaria del constitucionalismo. Para 1916, con el triunfo militar de esta fuerza revolucionaria frente al villismo y al zapatismo, y dada la carestía, inflación y especulación de bienes básicos, Carranza emitió una serie de decretos con la expresa finalidad de disminuir los efectos de la crisis e influir en la reanimación de la economía.

Con el arancel de $1916^{36}$ hubo un cambio en la política arancelaria, liberalizando y disminuyendo el proteccionismo. Se modificaron las tasas de importación y exportación, los artículos de consumo básico se exentaron o bajaron sus cuotas a menos de la mitad. También, se redujo la cuota en $10 \%$ a mantas, percales, calzado, así como a camisas de tela de algodón y de lana para mineros y jornaleros. Quedaron libres de derecho artículos para la educación, y herramientas de mano de todas las

${ }^{93}$ Ulloa, Historia, 1988, p. 246; Lerman, Comercio, 1989, p. 36, y Kuntz, "Comercio", 2001, p. 245

${ }_{35}$ Kuntz, Comercio, 2001, p. 269. pp. $341-342$.

${ }^{36} \mathrm{Si}$ bien este arancel hizo reformas a las cuotas de un buen número de artículos no tuvo un carácter general, continuando vigente la Ordenanza General de Aduanas anterior, la de 1891. Es hasta 1930 cuando se formó una nueva Ordenanza. Cosío, Cuestión, 1932, p. 18. Véase también Memoria, 1952, vol. II 
clases, carros y coches para vías fêrreas y embarcaciones. ${ }^{37}$ En cambio, se aumentaron los derechos de ropa de algodón ya terminada.

En 1917, con el nuevo ordenamiento constitucional, un cambio relevante en materia de impuestos fue la facultad adquirida por la federación para gravar las mercancías que se importen y exporten. Ciertamente, esta atribución ya estaba en la Constitución de 1857, la diferencia era que el ejecutivo podía ser facultado por el Congreso para disminuir o suprimir cuotas de las tarifas, así como restringir o prohibir las mismas, "a fin de regular el comercio exterior, la economía del país, la estabilidad de la producción nacional o realizar cualquier otro propósito, en beneficio del país" ${ }^{38}$ Así, era claro que el ejecutivo delineaba la política arancelaria como de hecho sucedió en los últimos años del régimen anterior, sólo que ahora quedaba constitucionalmente establecido.

En ese mismo año, estando Carranza ya como presidente constitucional, y teniendo facultades extraordinarias en materia hacendaria, se mantuvo la libre importación de alimentos, ${ }^{39}$ así como del oro, metal indispensable para el regreso a la circulación metálica. ${ }^{40}$ No obstante, el contexto externo era distinto: Estados Unidos entraba a la guerra europea y establecía una serie de restricciones a sus exportaciones. Los encargados de Hacienda tuvieron que emprender una serie de negociaciones para lograr que el gobierno estadunidense autorizara licencias de exportación a México, lo que se logró a finales de $1917 .^{41}$ Cabe señalar que, con la revolución y la guerra mundial se acentuaba una mayor dependencia comercial con el vecino país del norte, quien se convertía en el principal socio comercial.

Asimismo, el gobierno carrancista pretendió eliminar los gravámenes de importación a los artículos manufacturados de algodón y telas estam-

${ }^{37}$ Arroyo, Historia, 1937, p. 22
${ }^{38}$ Tena, Leyes, 1999, p. 877 .

${ }^{39}$ La producción agrícola para consumo interno fue el sector económico más afectado por la guerra. A la reducción de las áreas cultivadas por la inseguridad, se sumaron las malas cosechas. La tardanza de las lluvias, las heladas de los últimos meses; se sumaban a la ya crónic interrupción de las labores del campo, provocando la carestía de artículos básicos al finalizar el año de 1917. Excélsior, 27 de octubre de 1917.

${ }^{40}$ Como secuela de la guerra prevalecía un caos monetario por las continuas emisiones de papel moneda sin garantía, a finales de 1916 se optó por el regreso a la circulación metálica. Véase Kemmerer, Inflation, 1940.

${ }^{41}$ El encargado de Hacienda, Rafael Nieto, advertía que dado que México enviaba a Estados Unidos petróleo, metales y otros elementos indispensables para las manufacturas de la guerra, como henequén, guayule, pieles y ganado, debía, en correspondencia, ser completa la libertad de comercio entre México y Estados Unidos, pues México necesitaba trigo, harina, algodón, artículos manufacturados de algodón, maquinaria agrícola y minera, cables y alam bre. Excélsior, 25 de octubre 1917. Sobre la problemática que implicó la negociación de esta importaciones que demandaba el gobierno mexicano al estadunidense, véase Riguzzi, ¿Reciprocidad?, 2003, pp. 194-228. 
padas; además amenazó con la confiscación a las industrias que se mantuvieran en paro. ${ }^{42}$ Para los encargados de Hacienda los empresarios del textil mantenían precios altos de toda la ropa de algodón de uso general, pese a las medidas que se habían adoptado para suministrar algodón a sus industrias. ${ }^{43}$ Los textileros, por su parte, reaccionaron contra estas tarifas, presionando para obtener un mayor proteccionismo. ${ }^{44}$ Después de unas ríspidas negociaciones, Carranza tuvo que derogar los decretos librecambistas.

¿La intención de estas nuevas tarifas era modificar la política proteccionista del régimen anterior o sólo una forma de presionar a los propietarios para bajar sus precios? Como sabemos, los encargados de la $\mathrm{Ha}$ cienda Pública en esos años se guiaban por una buena dosis de pragmatismo, pues no existía una clara política económica que fijara las tasas arancelarias. Además, la debilidad del gobierno, impedía la efectividad de sus medidas. $\mathrm{El}$ nuevo régimen estaba inmerso en múltiples presiones: no tenía el dominio pleno del territorio nacional, contaba todavía con una frágil base institucional, carecía de canales adecuados de negociación con los diversos grupos de propietarios, era presionado por un creciente movimiento obrero que exigía mejores condiciones laborales, y tenía un gasto militar que ocupaba la mayor parte de su presupuesto. Es de suponer que, durante este periodo, el gobierno revolucionario emitió una serie de decretos que modificaron las tasas arancelarias para resolver los problemas económicos inmediatos que se le presentaron. En 1923 se estableció la Comisión de Aranceles que funcionó como un organismo encargado de fijar las cuotas de la tarifa de importación y exportación, y como una instancia negociadora con los propietarios para fijar las cuotas de los derechos a las importaciones. Y no fue sino hasta 1930 cuando se expidió una nueva Ordenanza General de Aduanas. ${ }^{45}$

No obstante, pese a las dificultades, sí existió entre el nuevo grupo una convicción favorable al librecambio. ${ }^{46}$ Como parte del nuevo discur

${ }^{42}$ Cabe señalar que, durante el porfiriato, la industria manufacturera, en general, creció amparada con tarifas proteccionistas y con prácticas monopólicas que le permitían mantener un margen de ganancias. Véase Haber, Industria, 1992, p. 240

El nuevo gobierno estableció la Comisión Reguladora de Algodón en La Laguna con el propósito de comprar las cosechas de los algodoneros y abastecer a los industriales nacionales. un esta region se coschaba $90 \%$ de la Y CONDUMEX, fondo XXI, leg. 6849

${ }^{4}$ Para Haber durante estos años los industriales básicamente presionaron al gobierno posrevolucionario para que mantuviera las prácticas de protección arancelaria y contra los artículos 27 y 123 de la nuva Constitución. Véase tambiến Ramírez Burguesía 1987, p. 207, y Collado, Empresarios, 1996, p. 208.

Sierra y Martínez, Historia, 1973, p. 260, y Riguzzi, "Política", 2001, p. 113. Collado, Empresarios, 1996, p. 224 
so revolucionario, y con un propósito legitimador, la dirigencia buscó siempre deslindar sus diferencias con el gobierno anterior; hubo constantes pronunciamientos contra los "privilegios" de las elites nacionales y extranjeras cobijados bajo el régimen anterior, y a favor de eliminar tarifas proteccionistas o exenciones de impuestos. ${ }^{47}$ Así, observamos que, por un lado, la política arancelaria carrancista formó parte de las negociaciones con los grupos de propietarios que, mediante prohibiciones o con la liberación de gravámenes, presionaba a los empresarios y buscaba llegar a acuerdos. Y, además, mostraba la intención del nuevo gobierno de eliminar privilegios a las elites y favorecer los intereses de las clases populares, que demandaban abaratar los precios de consumo básico.

Sin embargo, la beligerancia del discurso librecambista fue modificándose conforme avanzaron las negociaciones con los propietarios. En 1918 el presidente Carranza, en su informe, expresaba:

Las antiguas cuotas que tendían a impartir protección a la industria nacional, han sido en general reducidas, pues se ha considerado contrario a los intereses del país llevar más allá de un límite equitativo, sin más resultado que determinar una elevación en los precios con perjuicio del pueblo. Se ha procurado, por tanto, dejar una protección racional a las industrias viables, que se alimentan con materias primas de producción nacional, eliminando toda protección sobre algunas industrias exóticas, que no pueden tener vida dentro de la república. ${ }^{48}$

$\mathrm{Si}$ atendemos a este informe, vemos que las tesis radicales contra el proteccionismo se moderan. $\mathrm{Y}$ en la siguiente década, poco a poco se fueron registrando aumentos a los derechos de las importaciones, sobre todo a los bienes manufacturados que competían con la industria nacional, de tal modo que para 1930 podemos hablar de un mayor proteccionismo. ${ }^{49}$ Así, en los primeros años de esta década, estos gravámenes giran alrededor de $20 \%$ del total de los ingresos federales, pero, para 1930 , se observa un incremento que llega a representar 33\% (cuadro 1). Cabe decir que, pese a este aumento, los ingresos generados por las importaciones dejan de tener la relevancia del siglo XIX y pasan a ser un rubro más de los ingresos de la federación conforme los impuestos interiores cobraron relevancia. ${ }^{50}$

${ }^{47}$ Véase la prensa de la época controlada por el constitucionalismo como El Pueblo, El Demócrata, El Constitucionalista y, especialmente, El Economista.

${ }^{48}$ México, t. 4,1976, p. 324

43-45.

Ibid, p. 64. 
EL AUMENTO DE LOS DERECHOS A LAS EXPORTACIONES

En contraste con el comportamiento de las importaciones, las exportaciones crecieron por la demanda generada por la primera guerra mundial y la ubicación periférica de estas economías: productos agrícolas, ganaderos, metales y petróleo, permitieron su auge pese al conflicto bélico. ${ }^{51}$ Esta circunstancia fue aprovechada por el gobierno de Carranza gravando en forma sistemática los productos de exportación. Si bien estos derechos aumentaron desde los gobiernos de Madero y Huerta, con el constitucionalismo estos ingresos se convirtieron en parte fundamental de su política fiscal. EI Primer Jefe tuvo siempre interés en que las empresas, sobre todo las ligadas al sector exportador, continuaran sus trabajos. El 7 de junio de 1913 emitió una circular donde prohibía que se dispusiera de las propiedades extranjeras (excepto víveres, en caso de necesidad).$^{52}$ El 17 de octubre de 1914 estableció que

los derechos de exportación se pagaran en moneda oro de cuño nacional y teniendo en cuenta el ciudadano Primer Jefe que en algunas localidades escasea esta clase de monedas, para facilitar el pago de los derechos se dispone que se faculte a la Administración de Aduanas para que a falta de monedas de oro de cuño nacional, admita monedas de oro y plata o billetes de curso corriente de Estados Unidos al tipo de cambio de dos pesos por dólar y a falta de éstos acepte giros en dólares pagaderos a la vista en la plaza de Nueva York. ${ }^{53 .}$

Las nuevas autoridades de Hacienda coincidieron en el interés por gravar al sector exportador en manos del capital extranjero. ${ }^{54}$ Desde septiembre de 1914, dos meses antes de ser nombrado subsecretario de Hacienda, Rafael Nieto, a propósito de la grave situación económica ocasionada por la circulación de moneda sin garantía, había señalado la importancia de las exportaciones como el único recurso con el que contaba el país para tener fondos en el extranjero. Con la falta de captación

51 Véase Lerman, Comercio, 1989, pp. 33-64, y Kuntz, "Comercio", 2001, pp. 250-262. ${ }_{52}$ En general todas las fuerzas revolucionarias tuvieron un trato preferencial con las propiedades extranjeras, pues éstas representaban fuentes de divisas. CoNDUMEX, fondo XxI, leg. 398. Véanse también Zavala, "Impuestos", 1981, p. 349; Aguilar, Frontera, 1985, p. 317, y Uhthoff, Finanzas, 1998, p.63.

${ }_{53}$ Memoria, 1952, vol. I, p. 509, y Lerman, Comercio, p. 1989, pp. 54-55.

${ }^{53}$ Memoria, 1952, vol. I, p. 509, y Lerman, Comercio, p. 1989, pp. 54-55.
${ }^{4}$ Cabe señalar que existen distintas explicaciones sobre el interês del gobierno constitucionalista en gravar al capital extranjero, por ejemplo, para Katz, Carranza afectó a las empresas foráneas para no obtener recursos de las haciendas y favorecer a los propietarios nacionales. Pero, como se verá más adelante, a diversos propietarios nacionales, entre ellos los henequeneros, también se les cambió el régimen fiscal, por lo que tuvieron que hacer mayores contribuciones. Katz, Guerra, t. 1, 1982, p. 345. 
de capital foráneo y el crédito externo paralizado, sólo "se cuenta con el recurso de nuestras exportaciones, [por lo que se debe] procurar y proteger la exportación de todo lo que pueda tener mercado en el exterior". ${ }^{55}$ Para el constitucionalismo el control de este sector fue estratégico.

En estos años ocurrió el proceso contrario al periodo anterior, cuando disminuyeron los derechos a las exportaciones. Mientras las autoridades del antiguo régimen tuvieron la preocupación de reducir estos derechos para auspiciar la entrada de la inversión extranjera a este sector, así como favorecer a los productores nacionales que demandaban reducciones arancelarias, el nuevo gobierno aprovechaba la gran demanda generada por la guerra mundial y aumentaba los derechos. Al analizar esta nueva tendencia de gravar las exportaciones, en el contexto latinoamericano vemos que solamente los países que tuvieron una posición dominante en los mercados mundiales, como Perú en guano, Chile en nitratos minerales y Brasil en café, dispusieron altos gravámenes a los productos de exportación. ${ }^{56} \mathrm{El}$ caso de México era diferente, pues salvo en la producción del henequén, ${ }^{57}$ no controlaba la exportación de sus principales artículos. ${ }^{58}$

Así, poco a poco fueron gravadas las exportaciones; de comprender cinco productos se pasó a $93 .^{59} \mathrm{El}$ criterio fue tasar aquellas mercancías que salieran en forma de materia prima, pues de acuerdo con el secretario de Hacienda del constitucionalismo, Luis Cabrera, "toda materia prima exportada en bruto no beneficia directamente al pueblo mexicano y debe pagar por consiguiente un impuesto, y ese impuesto debe ser proporcional a los valores que poco a poco vayan saliendo en la forma de materias primas como el henequén, palo de tinte y otros productos".

A principios de 1915, mientras el gobierno de la Convención tenía el dominio de la mayor parte del territorio nacional, sobre todo las aduanas de la frontera norte, el constitucionalismo instalado en el puerto de Veracruz, la aduana más importante, dirigió todo su esfuerzo a controlar las zonas de exportación. ¿Én qué medida esta política arancelaria ayudó a inclinar la balanza a favor del carrancismo? Es difícil saberlo pero las cifras muestran la importancia del control de las aduanas para este

${ }^{55}$ Nieto, Más, 1922, p.113. fue el de los nitratos chilenos, que aportaron casi $50 \%$ del ingreso público entre 1890 y 1914 . Bulmer-Thomas, Historia, 2003, p. 134. Véase también Cárdenas, Ocampo y Thorp, Era, 2003 Tara Joseph el henequén yucateco, durante esos años, mantuvo virtualmente el monopoJoseph, Revolución, 1992, p. 38.

${ }_{58}$ Cárdenas, Ocampo y Thorp, Era, 2003, p. 27.

${ }_{59}$ El primer decreto que reformaba los derechos de exportación de la Ley de Ingresos de 1912-1913. Memoria, 1952, vol. I, pp. 429-431, y Zavala, "Impuestos", 1981, p. 341

${ }^{60}$ Diario de Debates de la Cámara de Diputados, 23 de julio de 1917. 
ejército en un momento en el que paralelamente se definía la lucha en el campo de batalla. ${ }^{61}$ Además de la de Veracruz, el constitucionalismo llegó a dominar las otras aduanas del Golfo y parcialmente las del Pacífico. Esto representaba contar con la mayor parte de los ingresos del comercio exterior. Si observamos los datos del cuadro 2 vemos la importancia que adquirieron los derechos de exportación, casi equiparables con los de importación. Esta relevancia destaca si tomamos en cuenta que, en el porfiriato, estos últimos sólo representaron $2 \%$ del total de los impuestos exteriores y $0.4 \%$ de los ingresos totales. También notamos la relevancia de las aduanas del Golfo que son precisamente las que controlaba el constitucionalismo, y por donde se exportaba el petróleo y el henequén.

Las exportaciones tuvieron un gran crecimiento en esta etapa. Sin embargo, no todos los artículos tuvieron la misma tendencia de crecimiento. Al respecto, Kuntz registra tres fases, la primera, de 1910 a 1914, cuando aumentaron las exportaciones agrícolas y disminuyeron los productos minerales; la segunda, de 1915 a 1918, que se caracterizó por un comportamiento fluctuante de los productos agrícolas y recuperación de los minerales; la última fase es cuando se presentó el gran auge del petróleo y un desempeño irregular de los productos agrícolas y mineros. ${ }^{62}$ ¿Hasta qué punto estas tendencias se reflejaron en los gravámenes? Con los datos que contamos, y tomando en cuenta sólo el comportamiento de los principales productos de exportación, metales, petróleo y henequén (cuadro 3), observamos que el monto recaudado por la exportación del henequén se mantuvo constante y muy alto durante estos años, con un repunte en 1916, terminando por ser la principal fuente de ingresos. Por su parte, en los primeros años el crecimiento de los derechos de los metales es bajo, pero para 1917 aumentaron más de cuatro veces. Esto coincide con la recuperación que señala Kuntz de los productos metálicos del segundo periodo. En contraste, los del petróleo crecieron a un ritmo menor, y no es sino hasta 1918 cuando ocurre su auge espectacular.

No obstante, a pesar de los dividendos que reportaron estos derechos, su establecimiento no fue sencillo. Para el nuevo gobierno implicó una serie de negociaciones con los propietarios extranjeros, así como con los nacionales dedicados a la exportación, pues, como es de suponer, se resistieron a pagar los nuevos impuestos. Ciertamente, ante la nueva legislación y la sujeción a un marco fiscal diferente, la oposición más beligerante la presentaron las compañías extranjeras, pero también los empresarios nacionales, como los henequeneros y los algodoneros, por

${ }^{61}$ En marzo de 1915 los constitucionalistas preparaban la ofensiva final contra las fuerzas convencionistas de Zapata y Villa,

${ }_{62}$ Kuntz, "Comercio", 2001, p. 251. 
CUADRO 2. DERECHOS A LA IMPORTACIÓN Y EXPORTACIÓN DE OCTUBRE DE 1914 A JUNIO DE 1915 (EN PESOS CORRIENTES)

Aduanas Derechos de importación Derechos de exportación

$\begin{array}{lrr}\text { Golfo } & 4745348.18 & \mathbf{4} 264685.15 \\ \text { Pacífico } & 198888.50 & 256065.04 \\ \text { Norte } & 263294.10 & 304219.12 \\ \text { Sur } & & 101768.80 \\ \text { Totales } & 5208350.50 & 4986737.11\end{array}$

Fuente: Boletín, 1915, t. 2.

CUADRO 3. INGRESOS DEL GOBIERNO POR EXPORTACIÓN DE METALES, PETRÓLEO Y HENEQUÉN (EN MILES DE PESOS ORO NACIONAL) 1914-1917

\begin{tabular}{lccc}
\hline Años & Metales & Petróleo & Henequén \\
& & & \\
1914 & 1722 & 1234 & 6785 \\
1915 & 2359 & 1943 & 6609 \\
1916 & 6671 & 3088 & 8292 \\
1917 & 10534 & 7553 & 5107 \\
Totales & 21288 & 13818 & 26793 \\
\hline
\end{tabular}

Fuentes: Memoria, 1952; Meyer, México, 1972; Ulloa, Historia, 1983, y Zuleta, "Invención", 2000.

lo que la aplicación de los nuevos gravámenes no fue continua y estuvo sujeta a múltiples variables, tanto las que provocó la guerra como las propias de la economía. Es decir, dependió, entre otros factores, del tipo de industria, de su ubicación geográfica (si estaba bajo el dominio territorial del constitucionalismo) y de su recepción de los nuevos impuestos, así como del ciclo económico del producto de exportación y su demanda en el mercado mundial. A continuación haremos una breve descripción de su aplicación para observar cómo se interrelacionan estas variables.

Para la industria minera, principalmente controlada por el capital estadunidense, ${ }^{63}$ la situación fue difícil durante la guerra por la afectación del transporte ferrocarrilero, por la falta de insumos para su producción, ${ }^{64}$ y también por su ubicación dispersa en diferentes regiones del país, pero

${ }^{63} 80 \%$ de la inversión minera provenía del capital estadunidense, $15 \%$ del britắnico y $2 \%$ del francés. Sariego, Estado, 1988, pp. 362-363. 


\section{$24 \quad$ Luz Maria Uhthoff Lopez}

principalmente en el norte, la zona más afectada por el conflicto bélico. Sin embargo, la gran demanda de metales durante la guerra europea, aunada a las disposiciones del constitucionalismo y otras fuerzas revolucionarias como el villismo para que, en la medida de lo posible, continuaran sus trabajos, permitieron mantener su producción, con las variantes señaladas anteriormente, desde luego.

Como es de suponer, el interés del constitucionalismo en proteger esta industria tenía como propósito recaudar los impuestos. Así, desde abril de 1914 los metales causaron un impuesto de pertenencia y otro de exportación al oro y a la plata. ${ }^{65} \mathrm{~A}$ principios de 1916 , Luis Cabrera, secretario de Hacienda del constitucionalismo, realizaba un recorrido por la región minera del norte para conocer la situación de esta industria y emprender pláticas con las empresas ${ }^{66}$ Cabe señalar que, en general, éstas procuraron tener una actitud más negociadora con las nuevas autoridades revolucionarias ${ }^{67}$ con el objetivo de mantener su producción y satisfacer la importante demanda del mercado mundial. ${ }^{68}$ Así, en ese mismo año, básicamente se definió el nuevo marco fiscal en que funcionaría esta industria. Se estableció que el oro y la plata causarían un impuesto de exportación de $10 \%$ ad valorem y los demás metales $5 \%$ (cuadro 4), especificándose que estas cuotas estaban sujetas a lo que dispusiera mensualmente la Secretaría de Hacienda. Los metales beneficiados en el país tuvieron $20 \%$ de descuento.$^{69} \mathrm{En}$ mayo del mismo año quedaban sujetos al impuesto interior del timbre los metales de exportación que se produjeran en la república o que procedieran de países extranjeros. ${ }^{70}$ Pero dicho gravamen tuvo que ser suspendido para reactivar la producción minera. En resumen, los metales tuvieron un aumento en el im-

$$
\begin{aligned}
& { }_{65}^{65} \text { Memoria, 1952, vol. I, pp. 531-532. } \\
& \text { El Demócrata, } 18 \text { de marzo de } 191 \\
& { }^{67} \text { Diversos autores han señalado que los mineros procuraron no enfrentarse directamente }
\end{aligned}
$$


CUADRO 4. IMPUESTOS DE EXPORTACIÓN A LOS METALES (PORCENTAJE EN PRECIOS DEL MERCADO)

Gobierno de Díaz (1905)

Gobierno de Carranza (1916)

$\begin{array}{llr}\text { Oro } & 2.5 & 10.0 \\ \text { Plata } & 2.5 & 10.0 \\ \text { Plomo } & 0.0 & 5.0 \\ \text { Cobre } & 0.0 & 5.0 \\ \text { Zinc } & 0.0 & 5.0\end{array}$

Zinc

Fuentes: Memoria, 1952, vol. I, y Gonzales, "Mine”, 1996

puesto sobre las pertenencias y sobre su exportación y por primera vez se gravaron los metales industriales: plomo, cobre y zinc. ${ }^{71}$

Como se sabe, con el regreso al orden constitucional en 1917, el régimen de propiedad cambió para las empresas mineras; algunas de estas medidas quedaron institucionalizadas en la Ley de 1919. En esta ley se establecieron tres impuestos anuales a las empresas mineras: el de la propiedad, el de la producción y el derecho de fundición, amonedación y ensaye. Así, se eliminaba temporalmente el impuesto extraordinario sobre exportación. En la siguiente década, los impuestos recaudados por esta actividad perdieron importancia, y sería hasta después de 1934, durante el régimen cardenista, cuando volvieron a tener relevancia en el conjunto de los ingresos federales. ${ }^{72}$

Para el control de la exportación del henequén, producción localizada en una región distante en la península de Yucatán, Carranza envió en 1915 a Salvador Alvarado como su principal "agente recaudador" ${ }^{33} \mathrm{La}$ llegada de Alvarado a la península coincidió con el auge en la exportación de esta fibra. ${ }^{74}$ El nuevo gobierno estableció en ese año un impuesto adicional al henequén exportado entre cinco centavos por kilo y $2.5 \mathrm{ad}$ valorem. En agosto se impuso otra contribución de un centavo por kilo cuando superara el precio de nueve pesos. Como se puede ver en el cuadro 3, aunque estas cifras son aproximadas, los gravámenes de esta fibra representaron en los años de 1914 a 1916 los ingresos más importan-

${ }^{71}$ El Pueblo, 30 de junio de 1916.

${ }_{72}$ En 1934 se expide una nueva Ley de Impuestos a la Minería. Cárdenas, "Revolución”, $2004,{ }_{73}$ pp. 117-122.

Alvarado era, junto con Álvaro Obregón, uno de los más importantes generales del constitucionalismo. Joseph, Revolución, 1992, p. 31.

${ }^{74}$ Durante el gobierno de Alvarado el precio del henequén exportado a Estados Unidos aumentó casi $400 \%$, pasando de 13.2 centavos por kilo en 1915 a más de 50.6 centavos (por poco tiempo) en 1918. Joseph, Revolución, 1992, p. 170. 
tes para el carrancismo, superior a los generados por los metales y el petróleo. ${ }^{75}$

A la llegada del constitucionalismo a esta zona, la producción henequenera estaba bajo el control de unas cuantas familias, entre 20 y 30 , una reducida oligarquía terrateniente que controlaba la vida política y económica del estado. ${ }^{76}$ Mientras que la actividad comercializadora quedaba a cargo de la empresa estadunidense Internacional Harvester Co., Alvarado se enfrentó a esta oligarquía modificando el tradicional sistema económico y social sobre bases más racionales, progresistas y capitalistas. ${ }^{77}$ Para ello estableció un mayor control gubernamental del sector exportador henequenero, permitiendo que los hacendados conservaran la propiedad de las plantaciones. A fines de 1915 reestructuró la Comisión Reguladora del Mercado del Henequén para obligar a los hacendados a vender su producción y tener el control del aparato comercializador de la fibra. ${ }^{78}$ Por su parte, la empresa comercializadora estadunidense Harvester emprendió una intensa actividad con el gobierno estadunidense para oponerse a las nuevas disposiciones que la desplazaban de su antiguo monopolio comercializador. También en 1918 se formó la Asociación de Hacendados Henequeneros a fin de presionar a favor de sus intereses al gobierno de Carranza.

Para fines de 1919 bajan los precios de la fibra, la Reguladora se declaró en quiebra y anunció la liquidación de sus activos, la Secretaría de Hacienda aprovechó para cobrarle impuestos atrasados a la exportación, y al no tener liquidez se procedió al embargo de sus propiedades. ${ }^{79} \mathrm{Lla}$ ma la atención que, ante la baja de los precios del henequén, el gobierno federal no redujera la carga impositiva, como lo había decretado con la minería, y, por el contrario, exigiera su pago, incluso sus adeudos. En esta ocasión Carranza no se enfrentaba a empresarios extranjeros, sino a uno de sus jefes militares, y si bien sus relaciones con éstos no eran del todo cordiales, lograba imponerse al poder regional de Alvarado, y obtener los codiciados recursos del henequén. Por ello Cabrera ${ }^{80}$ afirmaba:

${ }^{75} \mathrm{Joseph}$ muestra varios testimonios de la importante derrama de recursos estatales que pasaron a la . ${ }^{76}$ Joseph, Revolución, 1992 , pp. 62-66.

${ }^{7}$ Ibid, p. 121

${ }^{78}$ Zuleta, "Invención", 2000, 527

${ }^{70}$ Joseph comenta que el secretario de Hacienda, Luis Cabrera, sacó a remate toda la flota henequenera de Alvarado, privando así a Yucatán, y a todo el sureste de México, de una marina mercante independiente capaz de competir con las flotas extranjeras. Resulta sorprendente, señala este autor, que el gobierno federal no redujera la carga impositiva ante la baja de los precios de la fibra, y, por el contrario, exigiera su pago. Joseph, Revolución, 1992, p. 197.

${ }^{80}$ Cabe destacar la importante labor del secretario de Hacienda, Cabrera, en las negocia-
es con Alvarado. Él le indicaba al Primer Jefe los permisos y las ôrdenes que debían dărsele. Al respecto véase CONDUMEX, fondo XXI, exps. 8089, 8094 y 8097 . 
Yucatán ha salvado a la revolución pecuniariamente, Tabasco daba hombres y más hombres que iban a morir a Tampico, que iban a morir a Celaya... Sonora daba mucha sangre, Chihuahua daba mucha sangre... Yucatán daba mucho dinero, es cierto; hay que reconocerlo, hay que ponerlo en la balanza, no en el otro platillo, sino en el mismo platillo donde estaba la sangre de los demás hermanos, ¿de dônde habían de salir los fondos? No había otra fuente más que Yucatán en esos momentos. ${ }^{81}$

En la siguiente década, el henequén continuó siendo uno de los principales productos agrícolas de exportación, y la federación siguió cobrando los derechos de su exportación. No obstante, esta fibra no volvería a tener el gran crecimiento de los años de la primera guerra mundial.

Entre los productos de exportación, el petróleo tuvo una atención especial del constitucionalismo. En 1915 el Primer Jefe creó la Dirección Fiscal del Petróleo en la Secretaría de Hacienda y la Comisión Técnica del Petróleo adscrita a la Secretaría de Fomento. ${ }^{82}$ En agosto de 1916 decretó que todos los asuntos petroleros y mineros eran jurisdicción federal. Si bien el henequén y los metales proporcionaron importantes recursos al carrancismo, la demanda del petróleo tuvo su gran crecimiento ${ }^{83}$ precisamente cuando esta fuerza controló su exportación. ${ }^{84}$ Además, este energético permitió al nuevo gobierno desplegar su política nacionalista, cuyo fin era que las empresas extranjeras pagaran más impuestos y se sujetaran a una nueva reglamentación, y revindicar los derechos de la nación sobre los recursos del subsuelo, sustituyendo los títulos de propiedad que les fueron otorgados por concesiones durante el porfiriato.

Así, paralelamente al boom petrolero, ${ }^{85}$ se aplicaron nuevos gravámenes. Durante el gobierno de Madero se estableció el impuesto interior del timbre al petróleo en 20 centavos tonelada; con Huerta aumentó a 75 centavos. El 20 de junio de 1914 el constitucionalismo fijó el impuesto especial del timbre sobre petróleo crudo, "a razón de 60 centavos por tonelada", y estableció el derecho de barra sobre el petróleo crudo "a razón de diez centavos por tonelada, haciéndose en forma ordenada, en oro nacional, al dos por uno". ${ }^{86}$

${ }^{81}$ Diario de Debates de la Cámara de Diputados, 10 de julio de 1919.

${ }^{32}$ López Portillo, Petróleo, 1975, p. 37, y Brown, Petróleo, 1998, p. 234.

${ }^{83}$ Como se sabe, la producción de este energético durante la guerra mundial se volvió estratégica para los paises beligerantes; México se convirtó en el segundo productor mundial después de Estados Unidos, y en el primer exportador. Meyer, México, 1972, p. 175

${ }^{4}$ Cabe señalar que los constitucionalistas llegaron a las zonas petroleras en 1914, pero tuvieron que desalojarlas ante el poder de las fuerzas de Manuel Peláez, quien dominó la región hasta 1920. ${ }^{25}$ A partir de 1911 se inicia el periodo de gran producción, pero es sobre todo entre 1918 ${ }^{86}$ Memoria, 1952, vol. I, pp. 333-345. 
Durante el gobierno constitucional de Carranza, en 1917, con el propósito de fomentar el consumo interno del petróleo, se hicieron modificaciones al impuesto de producción, sólo se tasó el petróleo que se exportaba. Asimismo, se gravó en forma diferente el crudo y el refinado para estimular su industrialización. En $1921^{87}$ se fija un impuesto a su exportación.

Como se sabe, las compañías petroleras fueron las más beligerantes contra los nuevos impuestos y la reglamentación de los gobiernos revolucionarios. ${ }^{88}$ Desde la etapa preconstitucional ejercieron presión en el gobierno estadunidense para defender sus intereses. Pero es principalmente a raíz de la promulgación de la nueva Constitución, que su actividad fue más radical, se manifestaron abiertamente en contra de la reglamentación del artículo 27 constitucional y formaron una Asociación Norteamericana de Compañías Petroleras en defensa de sus intereses.

Ciertamente, fue en los años de 1918 a 1922 cuando se registró la mayor tensión entre los gobiernos revolucionarios y las compañías petroleras por los impuestos. ${ }^{89}$ Cabe decir que dichos años correspondieron a la etapa de mayor recaudación fiscal por este concepto. En gran medida ello obedeció a la mucha demanda y al desarrollo que experimentaron las empresas petroleras por el mercado mundial, ${ }^{90}$ así como a la mayor definición de los gravámenes a esta industria.

Durante la década de 1920 los gravámenes interiores del petróleo, como los de exportación, representaron uno de los rubros más importantes de los ingresos de la federación. A tal grado que los vaivenes de los ingresos estuvieron definidos en gran medida por la dinámica de la producción petrolera y su fiscalización. Si observamos el cuadro 1 notamos que con la introducción del impuesto a la exportación del petróleo en 1921 los impuestos a las exportaciones crecen más de cuatro veces de un año a otro, lo cual también se refleja en el aumento de los ingresos federales. En cambio, con la caída de la producción petrolera a partir de $1926,{ }^{91}$ los ingresos provenientes de este rubro descienden, de represen-

${ }^{87}$ Originalmente se estableció con la idea de cubrir el servicio de la deuda pública, pero después se le dio una aplicación general. Manterola, Petróleo, 1938, p. 342.

${ }^{8}$ Existe una extensa bibliografía que abunda sobre la resistencia de las compañ́as petroleras a los nuevos ordenamientos del constitucionalismo. Véanse, entre otros, Meyer, México, 1972 y Majestad, 1991, y Brown, Petróleo, 1998

${ }^{89}$ Las empresas peiroleras pagaban los impuestos bajo protesta. Además interpusieron ante la Suprema Corte una serie de amparos contra las medidas reglamentarias. Sus argumentos se basaron en la no retroactividad del artículo 27 constitucional y que al ejecutivo no le correspon-
diaslar sobre esta materia. Rippy, "Petróleo", 1959, p. 92. Manterola, Industria, 1938, p. 98.

${ }^{91}$ Diversos factores explican la caída de la producción petrolera. Uno de ellos fue un probalada geológico, pues algunos de los más grandes pozos petroleros fueron afectados por agua 
$\operatorname{tar} 10 \%$ de los ingresos federales en 1922 , pasan a $2 \%$ al finalizar la década. Además esta caída repercute en el conjunto de los ingresos. ${ }^{92}$

CONTINUIDAD O CAMBIO DESPUÉs DE LA REVOLUCIÓN

Durante este periodo, de 1872 a 1930 , los impuestos al comercio exterior siguieron siendo la base de los ingresos federales, lo que indica la importancia del sector exportador en la economía. Sin embargo, a lo largo de estos años, observamos una continua disminución, al pasar de $58.1 \%$ en 1872 a $35.8 \%$ en 1930 (cuadros 1 y 5). Este descenso obedeció, en principio, a la política económica del gobierno porfirista que buscó depender menos de los derechos sobre el comercio exterior, estableciendo el impuesto del timbre. Después, con la guerra revolucionaria, al disminuir las importaciones bajaron en general los derechos al comercio exterior. Para 1920, al finalizar la contienda, los aranceles llegaron a representar $30 \%$. Por primera vez estos gravámenes eran menos de la tercera parte de los ingresos totales. Ello se debió básicamente al crecimiento de los impuestos interiores, tanto por los nuevos impuestos del timbre a la minería y al petróleo, como por el considerable aumento de la contribución federal. $^{93}$ Esta tendencia a la baja de los ingresos del comercio exterior se mantuvo en los primeros años de la década de 1920; luego se registró un aumento, para llegar en 1928 a ser $38.3 \%$ (cuadro 5).

Como se puede ver en el cuadro 1 , los cambios que se registraron en los aranceles durante la década de 1920 estuvieron vinculados al comportamiento de los impuestos a las importaciones, cuya tendencia de crecimiento es muy clara al pasar de $23.1 \%$ en 1920 a 33.7\% en 1930 . En cambio, los derechos a las exportaciones tuvieron un comportamiento más fluctuante, muy ligado a los impuestos de la exportación del petróleo.

¿Qué efectos tuvo el proceso revolucionario sobre los aranceles? En primer lugar, la composición de los impuestos exteriores ya no dependía completamente de las importaciones, sino que las exportaciones fueron gravadas. Estos últimos derechos tuvieron una importancia fundamental

crudo van a la baja, y la competencia de los yacimientos venezolanos aumenta. Así, mientras en la década de 1920 la producción de petróleo mexicano va en descenso, Venezuela tiene un crecimiento notable, llegando a convertirse en el tercer mãs grande productor del mundo. Brown, Petróleo, 1997, pp. 319-320.

${ }^{92}$ Cabe aclarar que el crecimiento de las cifras expresadas en el cuadro 1 , tanto de los impuestos a la exportación como de los ingresos federales, es en términos nominales.

${ }^{93}$ La contribución federal se estableció en 1861 con el gobierno de Juárez, consistía en la aportación que hacían los estados y municipios a la federación, con lo que se apoyaba al revolución se aumentó a 60 por ciento. 
CUADRO 5. IMPUESTOS A LAS IMPORTACIONES Y EXPORTACIONES (1911, 1920 Y 1928) (EN PESOS CORRIENTES)

\begin{tabular}{lrcrcrc}
\hline & \multicolumn{3}{c}{ Total de } & Total de & Total de \\
& $1911-1912$ & ingresos (\%) & 1920 & ingresos (\%) & 1928 & ingresos (\%) \\
Importaciones & 42190 & 40.1 & 55228 & 23.1 & 104.742 & 34.9 \\
Exportaciones & 495 & 0.4 & 11031 & 4.6 & 10265 & 3.4 \\
Total & 45341 & 43.1 & 71992 & 30.2 & 115007 & 38.3 \\
\hline
\end{tabular}

Fuentes: Cuenta, 1913; Ilustración, 1923, y México, 1932.

durante el conflicto armado; después su peso fue menor y tuvieron un comportamiento fluctuante durante la década de 1920. También cambió la estructura tributaria; si la comparamos con la del antiguo régimen, observamos que de los cuatro rubros (impuestos sobre el comercio exterior, impuestos interiores que causan en toda la federación, impuestos interiores que causan en el Distrito Federal, y servicios públicos y ramos menores) que contenía, se pasa a diez, esto es a más del doble (cuadro 6), lo que indica una ampliación y diversificación de la base recaudatoria. En parte, ello se debió a la reforma hacendaria de 1924 que estableció el impuesto sobre la renta, ${ }^{94}$ pero sobre todo a los nuevos gravámenes al petróleo y a la minería, tanto los derechos de exportación como los impuestos interiores, estos últimos contenidos bajo los rubros de impuestos a la industria e impuestos y productos por la explotación de recursos naturales. Así, estos gravámenes mostraron las innovaciones más significativas en materia fiscal de la posrevolución.

En general, se puede decir que las variantes en los aranceles durante la década de 1920 se explican por diversas razones: por los efectos de los ciclos económicos internacionales en el comercio exterior; la recesión de 1921 al finalizar la guerra europea; la caída de la producción petrolera en 1926 y, por último, la crisis internacional de 1929, así como, por los problemas políticos, la endeble institucionalidad de esos años que afectan el desempeño del sector exportador. ${ }^{95}$ Es de notar el papel que empiezan a tener los ingresos por el petróleo durante esta década, sus cambios, debido tanto a la tasación fiscal como a los vaivenes de esta industria, afectan el conjunto de los ingresos federales. Así, en 1922, con la introducción del impuesto de la exportación del petróleo, se logró compensar la caída

${ }^{94}$ Aboites, Excepciones, 2003 , pp. 131-133.
${ }_{95}$ Kuntz, "Nuevas", 2002, p. 254. 


\section{CUADRO 6. ESTRUCTURA TRIBUTARIA}

\section{Antes de la revolución}

Impuestos al comercio exterior Impuestos interiores que causan en toda la federación ${ }^{\mathrm{a}}$

Impuestos interiores que causan en el Distrito Federal Servicios públicos y ramos menores
Después de la revolución

Derechos de importación

Derechos de exportación

Impuestos a la industria

Impuestos al comercio

Impuesto sobre la renta

Contribución federal

Impuesto del timbre

Impuestos y productos por la explotación de los recursos naturales especiales

Productos y aprovechamientos, compensa ción del Distrito Federal

Otros impuestos

a Este rubro incluye el impuesto del timbre y la contribución federal.

Fuentes: Memoria, 1912, y Memoria, 1926.

de los ingresos a las importaciones por el efecto del fin de la guerra mundial. Los derechos a las exportaciones crecieron casi cinco veces, mientras que los de las importaciones descendieron una tercera parte ${ }^{96}$ (cuadro 1). Y, después de 1926, se registra un decremento de los ingresos federales ocasionado por la caída de la producción petrolera.

\section{Comentario final}

Este trabajo buscó aproximarse a una visión de conjunto de la fiscalidad del comercio exterior entre 1872 y 1929. Estamos conscientes de que un estudio de la política comercial en un periodo tan importante amerita un análisis más profundo y detallado que tome en cuenta, entre otros aspectos, la relación de los aranceles con la dinámica del mercado internacional, el costo de los gravámenes en las economías de exportación o la forma en que se utilizayon internamente estos gravámenes.

Ciertamente, como se ha visto, la política arancelaria tuvo un papel importante en la integración de la economía mexicana en el mercado mundial, liberando las importaciones y, sobre todo, eliminando los

${ }^{96}$ Cabe aclarar que su crecimiento es en términos nominales. 


\section{Luz María Uhthoff López}

gravámenes a las exportaciones. También a partir de la década de 1890 e gobierno de Porfirio Díaz llevó a cabo una política arancelaria favorable al desarrollo de la industria nacional, racionalizando las tarifas impositivas, de tal manera que se protegió a las manufacturas internas de sus competidoras extranjeras. Para la etapa de la revolución mexicana, pese a la ruptura política que conllevó la contienda armada, el comercio exterior se mantuvo y, en algunas ramas, experimentó un importante desarrollo, por tanto, los ingresos provenientes de este sector continuaron siendo importantes. No obstante, la contienda revolucionaria aceleró la caída de estos impuestos en el conjunto de los ingresos federales, pasando de ser casi la mitad a la tercera parte. También cambió la estructura tributaria, al introducir nuevos gravámenes a la producción y exportación del sector externo, básicamente en manos del capital foráneo. Con ello los nuevos gobiernos se alejaban de la tradicional política del antiguo régimen, ${ }^{97}$ y buscaban entablar una diferente relación con la inversión extranjera, imponiendo un trato igual a los actores económicos independientemente de si son nacionales o extranjeros.

Se observa, así, durante el periodo de 1872 a 1930 , una tendencia a la baja de los impuestos provenientes del comercio exterior, y también una disminución de su importancia en el conjunto de los ingresos federales. Lo que indica que existió en los gobiernos de esos años, tanto de la primera como de la segunda etapa, la preocupación de no depender solamente de estos ingresos, y buscaron fuentes alternativas de ingresos internos, como el impuesto del timbre y el impuesto sobre la renta.

\section{ARCHIVOS}

CONDUMeX

Hemerografía

Excélsior, ciudad de México.

El Demórata, ciudad de México.

El Pueblo, ciudad de México.

El Constitucionalista, Veracruz.

El Economista, ciudad de México.

Diario de Debates de la Cámara de Diputados, ciudad de México.

${ }^{97}$ Katz, Guerra, 1992, t. 1, p. 364. 
BiBLIOGRAFÍA

ABOITES AGUILAR, LUIS, Excepciones y privilegios: modernización tributaria y centralización en México, 1922-1972, México, Colmex, 2003.

AgUILAR CAMÍn, HÉctor, La frontera nómada y la revolución mexicana, México, Siglo XXI, 1979.

Arroyo CROETTE, CARLOs, Historia de los aranceles aduaneros mexicanos y de su influencia en nuestro comercio exterior, mecanografiado, México, 1937.

BEATTY, EDWARD, Institutions and investment, the political basis of industrialization in Mexico before 1971, Stanford, California, Stanford University Press, 2001. "Commercial policy in Porfirian Mexico: the structure of protection" en JeFFREY BORTZ y STEPHEN HABER (eds.), The mexican economy, 1870-1930, essays on the economic history of institutions, revolution and growth, Stanford, California, Stanford University Press, 2002.

"Visiones del futuro: la reorientación de la política económica en México (1867-1893)", Signos Históricos, núm. 10, julio-diciembre, 2003, México.

BernsteIn, Marvin D., The Mexican Mining Industry, 1890-1950, a Study of the Interaction of Politics, Economics and Technology, Albany, Nueva York, State University of New York, 1964.

Boletin de estadística fiscal, México, Secretaria de Hacienda y Crédito Público, 1915. BROWN, JONATHAN C., "Empresa y política: cómo y por qué se nacionalizó la industria petrolera” en CARlos Marichal y Mario CeruTti (comps.), Historia de las grandes empresas en México, 1850-1930, México, FCE, 1997, pp. 317-344. , Petróleo y revolución en México, México, Siglo XXI, 1998.

Bulmer-Thomas, Víctor, La historia económica de América Latina desde la independencia, México, FCE, 2003

CÁRdenAs, ENRIQUe, José ANTONIO OCAMPO y Rosemary Thorp (comps.), La era de las exportaciones Latinoamericanas. De fines del siglo XIX a principios del XX, México, FCE, El Trimestre Económico, 2003 (Lecturas, 93).

CÁRDENAS, NiCOLÁS, "Revolución y desarrollo económico: el caso de la minería", Signos Históricos, núm. 11, enero-junio 2004, pp. 97-137.

CARMAGNANI, MARCELlo, Estado y mercado. La economía pública del liberalismo mexicano 1850-1911, México, FCE, 1994.

Collado Herrera, María del Carmen, Empresarios y políticos, México, Instituto Nacional de Estudios Históricos de la Revolución, 1996.

Cóndova, ARNALdo, La ideología de la revolución mexicana. La formación del nuevo régimen, México, Era, 1973.

CORTÉS CONDE, "El crecimiento de las economías latinoamericanas, 1880-1930", Historia Mexicana, vol. 42, núm. 3, enero-marzo de 1993, pp. 633-647.

Cosío Villegas, Daniel, La cuestión arancelaria en México, México, Secretaría de Hacienda y Crédito Público, 1940. 
Cuenta de la Hacieda pública federal 1911-1912, México, Tipografía de la Oficina Impresora de Estampillas, Palacio Nacional, 1913

Decretos, circulares y demás disposiciones emitidas por el gobierno constitucionalista por conducto de la Secretaría de Hacienda (de abril de 1913 al 31 de diciembre de 1915), México, Secretaría de Hacienda, 1916.

GonZales, MichaelJ., "'The Mine Workers' Movement, and the Mexican Revolution, 1910-1920", Hispanic American Historical Review, vol. 76, núm. 3, agosto de 1996, pp. 503-534.

Gómez-Galvarriato, Aurora y Aldo Musacchio, "Un nuevo índice del costo de la vida en México, 1886-1930", Trimestre Economico, vol. 67, núm. 1, 2000, pp. 47-91.

HABER, STEPHEN, Industria y subdesarrollo. La industrialización de México, 1890-1940, México, Alianza Editorial, 1992.

HERNÁNDEZ ChÁvEZ, ALICIA, "Militares y negocios en la revolución mexicana", Historia Mexicana, vol. 34, núm. 2, octubre-diciembre, 1984, pp. 181-212.

Ilustración Gráfica de los Ingresos, 1917-1922, México, Departamento de Estadística de la H. Cámara de Diputados, 1923.

Joseph, Gilbert M., Revolución desde afuera. Yucatán, México y los Estados Unidos 18801924, México, FCE, 1992

KATZ, Friedrich, La guerra secreta en México, México, Lra, 1982, 2 vols. , Pancho Villa, México, Era, 1998, 2 vols.

KEMMERER, EDWIN, Inflation and Revolution, Mexico's Experience of 1912-1917, Princeton, Princeton University Press, 1940.

KuNTZ FICKER, SANDRA, "El comercio exterior durante la década revolucionaria: un acercamiento preliminar", Política y Cultura. Estudios de Historia de México, Siglos $X I X$ y XX, UAM-X, núm. 16, otoño de 2001, pp. 235-274.

, "Nuevas series del comercio exterior de México, 1870-1929", Revista de Historia Económica, vol. Xx, núm. 2, 2002, pp. 213-270.

"Institutional Change and Foreign Trade in Mexico, 1870-1905" en JEFFREY BORTZ y STEPHEN HABER (eds.), The Mexican Economy, 1870-1930: Essays on the Economic History of Institutions, Revolution and Growth, Stanford, California, Stanford University Press, 2002, pp. 161-203.

LÓpez Portillo y Weber, Josê, el petróleo de México: su importancia, sus problemas, México, FCE, 1975.

LeRMAN Al.PERSTEIN, AfDa, Comercio exterior e industria de transformación en México, 1910-1920, México, UAM-X/Plaza y Valdés, 1989.

Manterola, Miguer, La industria del petróleo en México, México, Oficina de Gráficas, Secretaría de Hacienda y Crédito Público, 1938.

MÁrouez Colf́n, Graciela, "Los impuestos al comercio exterior: del porfiriato a la gran depresión", ponencia presentada en el Primer Congreso de Historia Económica, México, octubre de 2002.

The Political Economy of Mexican Protectionism, 1868-1911, Cambridge, Massachussetts, G. García Colín, 2002. 
Memoria de la Hacienda y Crédito Público correspondiente al año económico de 1 de julio de 1910 a 30 de junio de 1971, presentada por el secretario de Hacienda al Congreso de la Unión, México, Tipografía de la Oficina Impresora de Estampillas, 1912.

Memoria de la Hacienda y Crédito Público correspondiente a los años fiscales de 1923-19241925, México, Cultura, 1926, 2 vols.

Memoria de la Hacienda y Crédito Público del 23 de febrero de 1913 al 15 de abril de 1917, México, Secretaría de Hacienda y Crédito Público, Publicaciones Históricas, 1952,13 vols.

México a través de los informes presidenciales, La Hacienda Pública, México, Secretaría de Hacienda y Crédito Público/Secretaría de la Presidencia, 1976, t. 4.

México Económico, 1928-1930, Anuario Estadístico de la Oficina de Estudios Económicos de los Ferrocarriles Nacionales de México, México, Cultura, 1932.

Meyer, Lorenzo, México y los Estados Unidos en el conflicto petrolero (1977-1942), México, Colmex, 1972

Los grupos de presión extranjeros en el México revolucionario, México, Secretaría de Relaciones Exteriores, 1977.

Su majestad británica contra la revolución mexicana, 1900-1950. El fin del imperio informal, México, COLMEX, 1991.

Nieto, Rafael, Más allá de la patria, México, Cultura, 1922.

PAOLi Bolio, Francisco Josê, Yucatán y los orígenes del nuevo Estado mexicano, México, Era, 1984.

Pani, Alberto J., La política hacendaria y la revolución, México, Cultura, 1926.

Pérez Siller, Javier, "Los ingresos federales en México: 1867-1913", México, tesis de licenciatura, UNAM, 1982, 2 tt.

, La fiscalidad, un observatorio para el historiador. Ensayo historiográfico sobre el Porfiriato, Puebla, Instituto de Ciencias Sociales y Humanidades-BUAP/Asociación ALEPH, París, 1999.

Ramírez RanCAÑo, Burguesía textil y política en la revolución mexicana, México, unam, 1987.

RuguzZi, PAOLO, "La política comercial en México, 1856-1930: fuentes y problemas", América Latina en la Historia Económica, Boletín de Fuentes, núm. 15, enero-junio de 2001, pp. 107-115.

¿Recipracidad imposible? La política del comercio entre México y Estados Unidos, 1857-1938, México, El Colegio Mexiquense/Instituto Mora, 2003.

RIPPY, MERRILL, "El petróleo y la revolución mexicana", Problemas Agrícolas e Industriales de México, julio-septiembre de 1954, pp. 9-180.

Sariego, JuAn Luis et al., El Estado y la mineria mexicana. Política, trabajo y sociedad durante el siglo XX, México, $\mathrm{FCE} /$ Instituto Nacional de Antropología e Historia/ Secretaría de Energía, Minas e Industria Paraestatal/Comisión de Fomento Minero, 1988.

Servín, ARMANDo, "Nuestra política tributaria de 1869 a 1911", El Trimestre Económico, vol. 8, 1940, pp. 450-462. 
Sierra, Carlos J. y Rogelio Martínez Vera, Historia legislación aduanera de México, México, Secretaría de Hacienda y Crédito Público, 1973.

Sterret, Davis y Joseph S. Davis, "Situación económica" en Enrique Cárdenas (comp.), Historia económica de México, México, FCE, 1994, t. 4, pp. 33-172.

Tena Ramírez, Felipe, Leyes fundamentales de México, 1808-1999, México, Porrúa, 2000.

Topik, Steven y Allan Welis (eds.), The Second Conquest of Latin America, Cofeee, Henequen and Oil During the Export Boom, 1850-1930, Austin, University of Texas Press, 1998.

UHTHOFF LOPEZ, LUZ MARÍA, Las finanzas públicas durante la revolución. El papel de Luis Cabrera y Rafael Nieto al frente de la Secretaría de Hacienda, México, UAM, 1998.

ULLOA, BeRTA, Historia de la revolución mexicana, la Constitución de 1977, México, Colmex, 1983.

YANẼEZ RUIZ, MANUEL, El problema fiscal en las distintas etapas de nuestra organización política, México, Secretaría de Hacienda y Crédito Público, 1959, 6 vols.

ZaVALA, EsTELA, "Los impuestos y los problemas financieros de los primeros años de la revolución", Historia Mexicana, vol. XxxI, núm. 3, enero-marzo de 1982, pp. 325-360.

ZEBAdÚA, EMILIO, Banqueros y revolucionarios: la soberanía financiera de México, 19141929, México, FCE/ColmeX, 1994.

Zuleta, MARfa CECILIA, "La invención de una agricultura próspera. Itinerarios del fomento agrícola entre el porfiriato y la revolución, 1876-1915”, México, tesis de doctorado, COLMEX, 2000. 


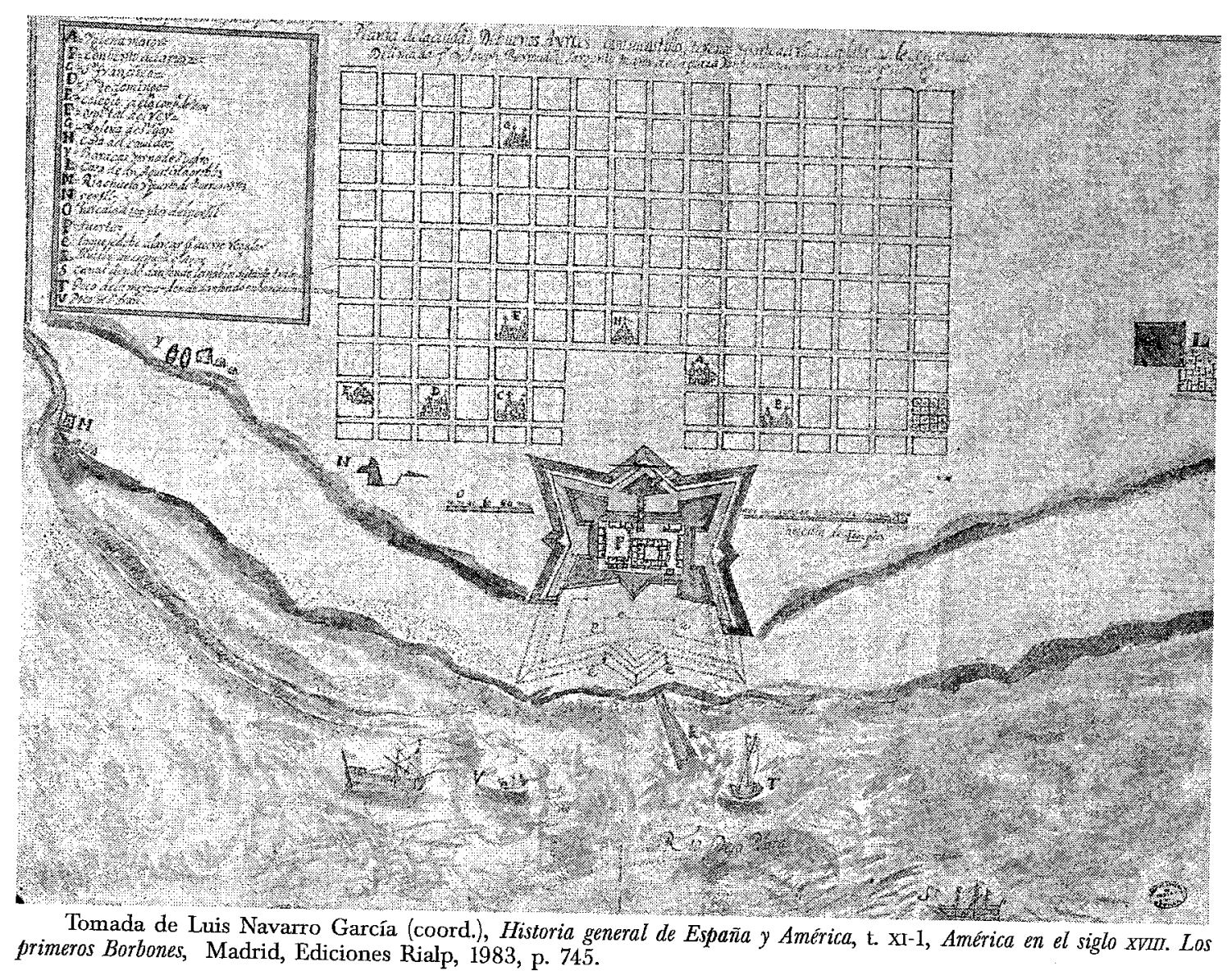

